www.jmscr.igmpublication.org

Impact Factor (SJIF): 6.379

Index Copernicus Value: 79.54

ISSN (e)-2347-176x ISSN (p) 2455-0450

crossrefDOI: https://dx.doi.org/10.18535/jmscr/v6i9.42

Journal Of Medical Science And Clinical Research

IGM Publication

An Official Publication of IGM Publication

\title{
Observation of lipid profile in individuals suffering from diabetes mellitus of different age groups, sex and socioeconomic status in Bihar
}

\author{
Authors \\ Mamta Kumari $^{1}$, R.V.N Singh ${ }^{2}$ \\ ${ }^{1}$ Senior Resident, Department of Pathology, All India Institute of Medical Science, Patna, Bihar, India \\ ${ }^{2}$ Ex-Professor and Head, Department of Pathology, Patna Medical College and Hospital, Patna, Bihar, India \\ Corresponding Author \\ Dr Mamta Kumari \\ Department of pathology, All India Institute of Medical Science, Patna, Bihar, India, 801507 \\ Email:mdoc659@gmail.com
}

\begin{abstract}
Introduction: Diabetes mellitus is a clinical syndrome characterized by hyperglycemia due to absolute or relative deficiency of insulin hormone. Type 2 Diabetes mellitus (DM) is characterized by insulin resistance, impaired insulin secretion and increase glucose production. Type 1 diabetes mellitus results from a severe absolute lack of insulin caused by a reduction in beta cell mass.

Material and Methods: For the present study the cases were selected from those non insulin dependent diabetics patient (NIDDM) attending the diabetic clinic of Patna medical college and hospital, Patna. Normal healthy person (control) of comparable age groups was taken from staffs, attendants of indoor and outdoor patients.
\end{abstract}

Results: Serum total cholesterol (TC) level in diabetic patients (type 2 NIDDM) was higher in above 40 yrs group than below 40 years group in both male and female. But in comparison to control of similar age and sex groups there was no significant alteration in the total cholesterol level of diabetic patients. Serum high density lipoprotein $(H D L)$ cholesterol level in diabetic group was significantly lower to control of comparable age groups in both male and female. Serum HDL cholesterol level in diabetic groups of male and female were found not to be influenced by severity or duration of the disease.

Conclusion: From our study it was concluded Diabetes mellitus has a real impact on carbohydrate, protein and fat metabolism.

Keywords: Diabetes mellitus. Total cholesterol, Non insulin dependent diabetes mellitus, High density lipoprotein.

\section{Introduction}

Diabetes mellitus is a clinical syndrome characterized by hyperglycemia due to absolute or relative deficiency of insulin hormone. Type 2 Diabetes mellitus (DM) is characterized by insulin resistance, impaired insulin secretion and increase glucose production. ${ }^{1}$ Type 1 DM results from a severe, absolute lack of insulin caused by a reduction in beta cell mass. The destructive process is almost certainity autoimmune in nature. There is 366 million people living with DM worldwide (2011). ${ }^{2}$ India contribute to nearly one 
sixth of global diabetes burden in 2011 with about 62 million of people affected by diabetes which is supposed to rise to 101 million by $2030 .^{2,3}$ Type 2 DM is the most prevalent form of DM seen in India and constitutes more than 95\% diabetes population. Prevalence of diabetes is increasing in India. According to NUDS, Daryaganj survey and CURE study, Type 2 DM occurs a decade earlier than in the developed world ${ }^{4,5,6}$. The metabolic abnormalities commonly seen in diabetes are disturbances in the production and clearance of plasma lipoproteins. In India prevalence of dyslipidemia is $85.5 \%$ in male Type $2 \mathrm{DM}$ and $97.8 \%$ in female Type 2 DM. $^{7}$ Diabetes mellitus is associated with an increased incidence of Ischaemic heart disease with a tendency to diffuse coronary atheroma. This relation has been observed in many studies. Plumbo et al (1976) observed that coronary artery atherosclerosis is more commonly present in patients with diabetes. The common form of dyslipidemia is hypertriglyceridemia and reduced HDL cholesterol. The small LDL particles found in Type $2 \mathrm{DM}$ are more atherogenic because they are easily glycated and oxidized. ${ }^{8}$

\section{Material and Methods}

Cases (80) were selected from those non-insulin dependent diabetics patients attending the diabetic clinic of Patna medical college and hospital, Patna. Normal healthy persons (control)of comparable age groups were taken from staffs, attendants of indoor and outdoor patients. After proper history cases were asked to report next morning in the empty stomach.Blood from vein was withdrawn for estimation of fasting sugar, total cholesterol, HDL cholesterol and LDL cholesterol.

1-Blood sugar estimation-reagents

a) $3.0 \% \mathrm{~W} / \mathrm{V}$ Trichloroacetic acid

b)O-Toluidine reagent

c) Stock standard glucose solution

2-Estimation of total cholesterol-

Cholesterol reagent (ready to use kit of pointe scientific from Ranbaxy Diagnostics) contain:4 aminoantipyrine $2.0 \mathrm{~mm}$, sodium cholate $10 \mathrm{MM}$, cholesterol esterase $250 \mathrm{u} / \mathrm{l}$, horseradish peroxidase $500 \mathrm{ILI} / \mathrm{L}$, sodium hydroxybenzoate $5 \mathrm{~mm}$, surfactant, buffer, $\mathrm{ph}=7.5$, non reactive stabilizes and fillers, with sodium azide(0.01\%)as preservative.

3-Estimation of HDL Cholesterol

Kit content (of Ranbaxy)

Reagent 1-Precipitating reagent glycine buffer$\mathrm{ph}=10.2 \mathrm{PEG} 6000-10 \mathrm{mg} / \mathrm{dl}$.

Reagent 2-cholesterol standard 50mg/dl

4-Estimation of LDL cholesterol

LDL cholesterol=total cholesterol-cholesterol in the supernatant

Sample-serum

1-Precipitation reagent (from Ranbaxy)

Heparin-50,000IU/ml

Sodium citrate: $0.064 \mathrm{~mol} / \mathrm{l} \mathrm{ph}-5.04$

2-Reagent solution (CHOD-PAP)

\section{Results}

In the present study 80 controls and 80 diabetic patients were investigated . They were in the age group of 28-60 years. All the normal controls were studied for fasting blood sugar, blood sugar 2 hours after $75 \mathrm{gm}$. of oral glucose -intake, serum total cholesterol, serum HDL cholesterol and LDL cholesterol. Similarly in all diabetic patients fasting blood sugar, total cholesterol, HDL cholesterol, LDL cholesterol were studied. And also blood sugar were estimated 2 hours after taking meal. The cholesterol level is known to increase with age and its level in men below 40 years of age is higher than women of the same age where as women at 50 years or more starts to taking lead to men. 


\section{JMSCR Vol||06||Issue||09||Page 241-249||September}

Chart-1A: histogram showing mean total cholesterol HDL, LDL cholesterol (in $\mathrm{mg} / \mathrm{dl}$ ) in normal men and women below and above forty(40) years of age and the comparison between the two age groups.

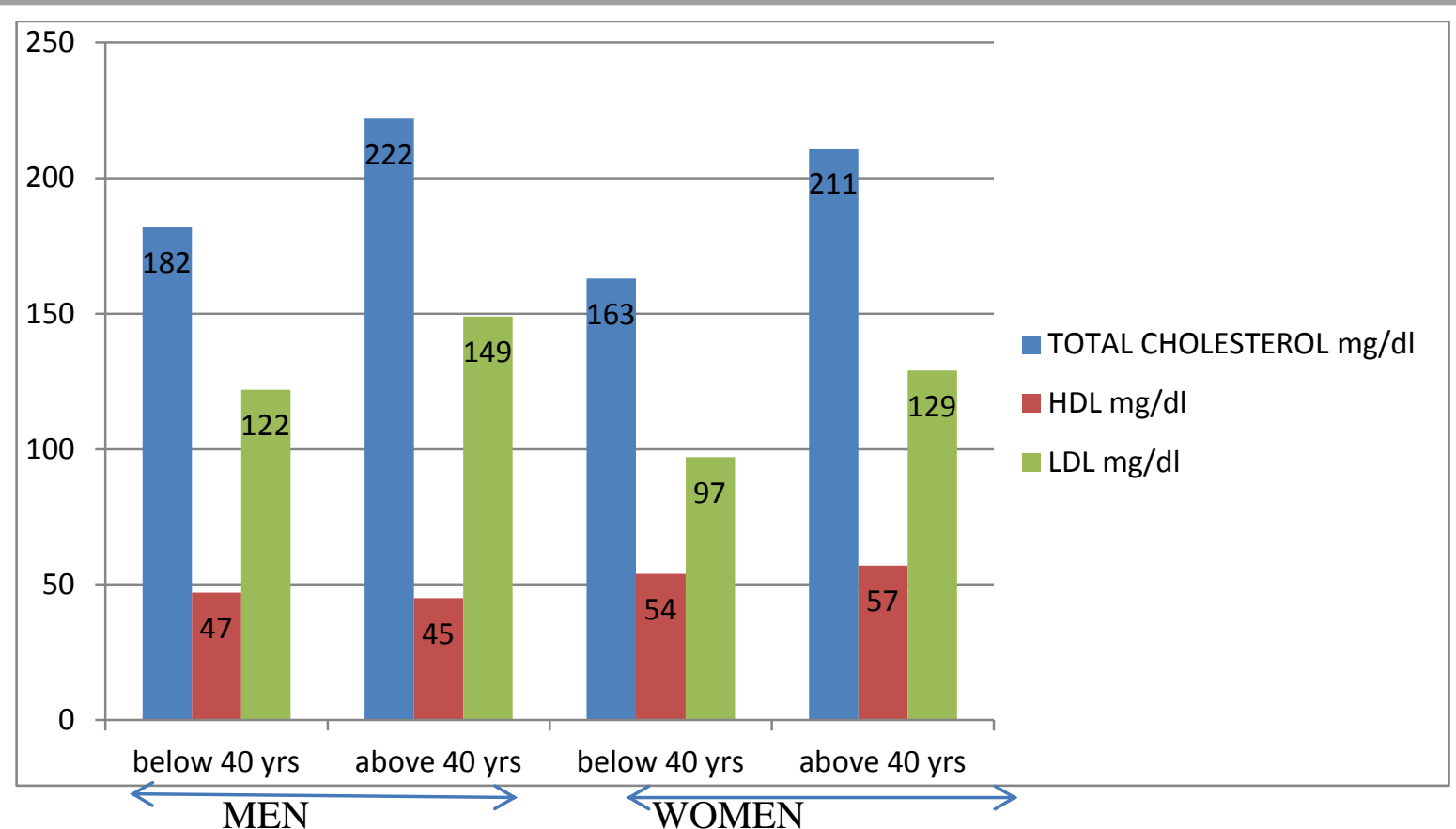

Chart-1B: histogram showing means serum cholesterol HDL \&LDL (mg/dl) in normal men and women and comparison between them.

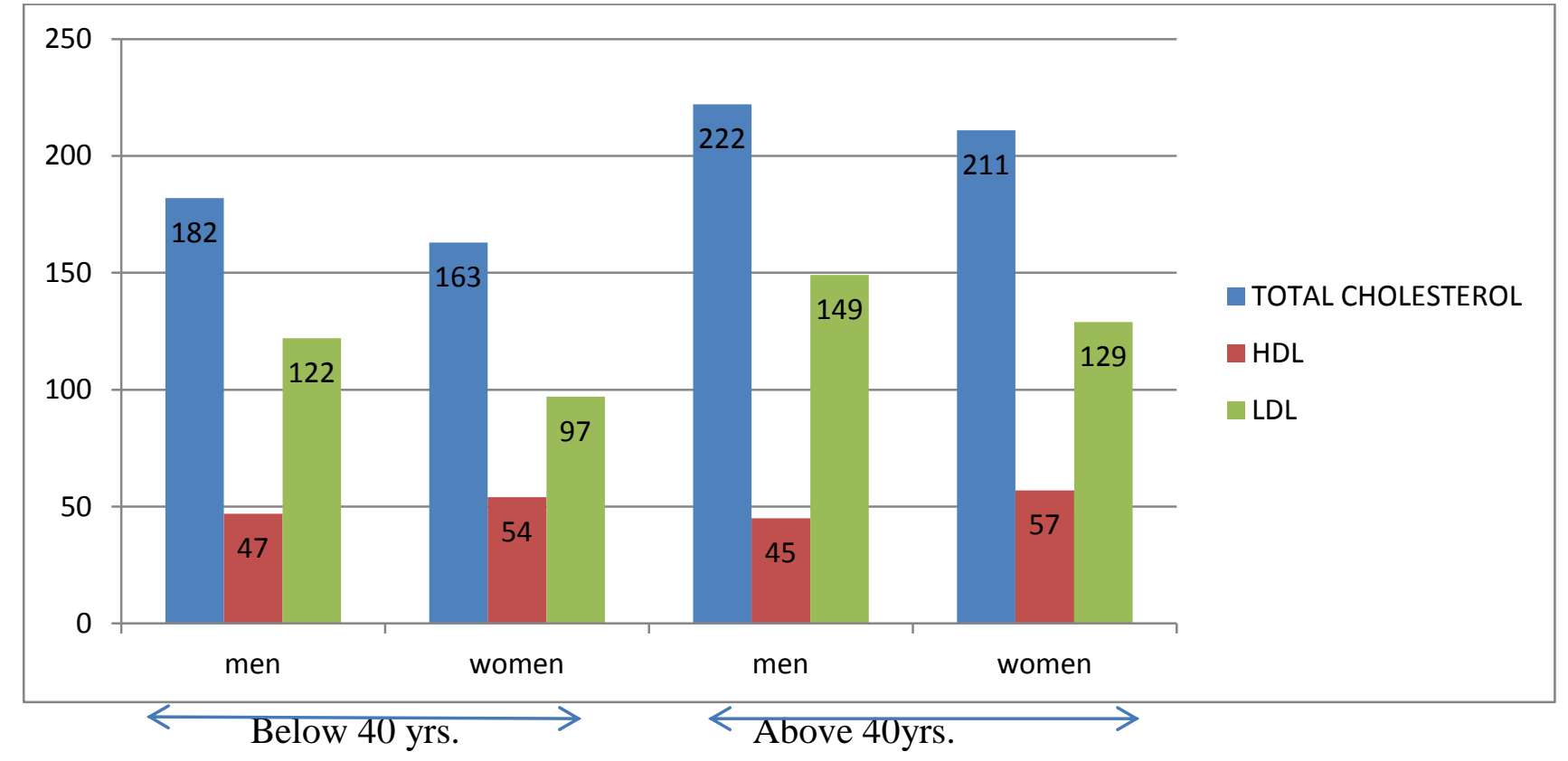

Table-1A Showing mean total cholesterol, HDL and LDL cholesterol (in $\mathrm{mg} / \mathrm{dl}$ ) in normal men and women below above forty (40) years of age and comparison between the two are groups.

\begin{tabular}{|l|c|c|c|c|c|}
\hline GROUP & & $\begin{array}{c}\text { NO OF } \\
\text { PTS }\end{array}$ & $\begin{array}{c}\text { TOTAL CHOLESTEROL } \\
\mathrm{mg} / \mathrm{dl}\end{array}$ & $\begin{array}{c}\text { HDL } \\
\mathrm{mg} / \mathrm{dl}\end{array}$ & $\begin{array}{c}\text { LDL } \\
\mathrm{mg} / \mathrm{dl}\end{array}$ \\
\hline MEN & Below 40 years & 20 & 182 & 47 & 122 \\
\hline & Above 40 years & 20 & 222 & 45 & 149 \\
\hline WOMEN & Below 40 years & 20 & 163 & 54 & 97 \\
\hline & Above 40 years & 20 & 211 & 57 & 129 \\
\hline
\end{tabular}




\section{JMSCR Vol||06||Issue||09||Page 241-249||September}

Table-1B Showing mean serum cholesterol, HDL, LDL, (mg/dl) in normal men and women and comparison between them.

\begin{tabular}{|l|c|c|c|c|c|}
\hline GROUP & & $\begin{array}{c}\text { NO OF } \\
\text { PTS }\end{array}$ & $\begin{array}{c}\text { TOTAL CHOLESTEROL } \\
\mathrm{mg} / \mathrm{dl}\end{array}$ & $\begin{array}{c}\text { HDL } \\
\mathrm{mg} / \mathrm{dl}\end{array}$ & $\begin{array}{c}\text { LDL } \\
\mathrm{mg} / \mathrm{dl}\end{array}$ \\
\hline BELOW 40 YRS & MEN & 20 & 182 & 47 & 122 \\
\hline & WOMEN & 20 & 163 & 54 & 97 \\
\hline ABOVE 40 YRS & MEN & 20 & 222 & 45 & 149 \\
\hline & WOMEN & 20 & 211 & 57 & 129 \\
\hline
\end{tabular}

It is obvious from table $1 \mathrm{~A}$ that

i. The total cholesterol and LDL cholesterol level in men and women were significantly lower in age group below 40 years than that above 90 years.

ii. HDL cholesterol level in men in the age group below 40 years is not significantly different from these above 40 years of age. But in women of age group above 40 years, it is significantly higher than that of women of age group below 40 years.
Inferences from table 1B are that

I. The total serum cholesterol in age group below 40 years and LDL cholesterol in the age group below 40 and above 40 years, were significantly higher in men than that in women. The total cholesterol level in men and women above 40 years age group was not much different.

II. In both age groups the level of HDL cholesterol in women in higher than those of men of respective age group.

Chart-2A: Histogram Showing Mean Total Cholesterol, HDL and LDL Cholesterol (in mg/dl) in Type-2 Diabetic Patients

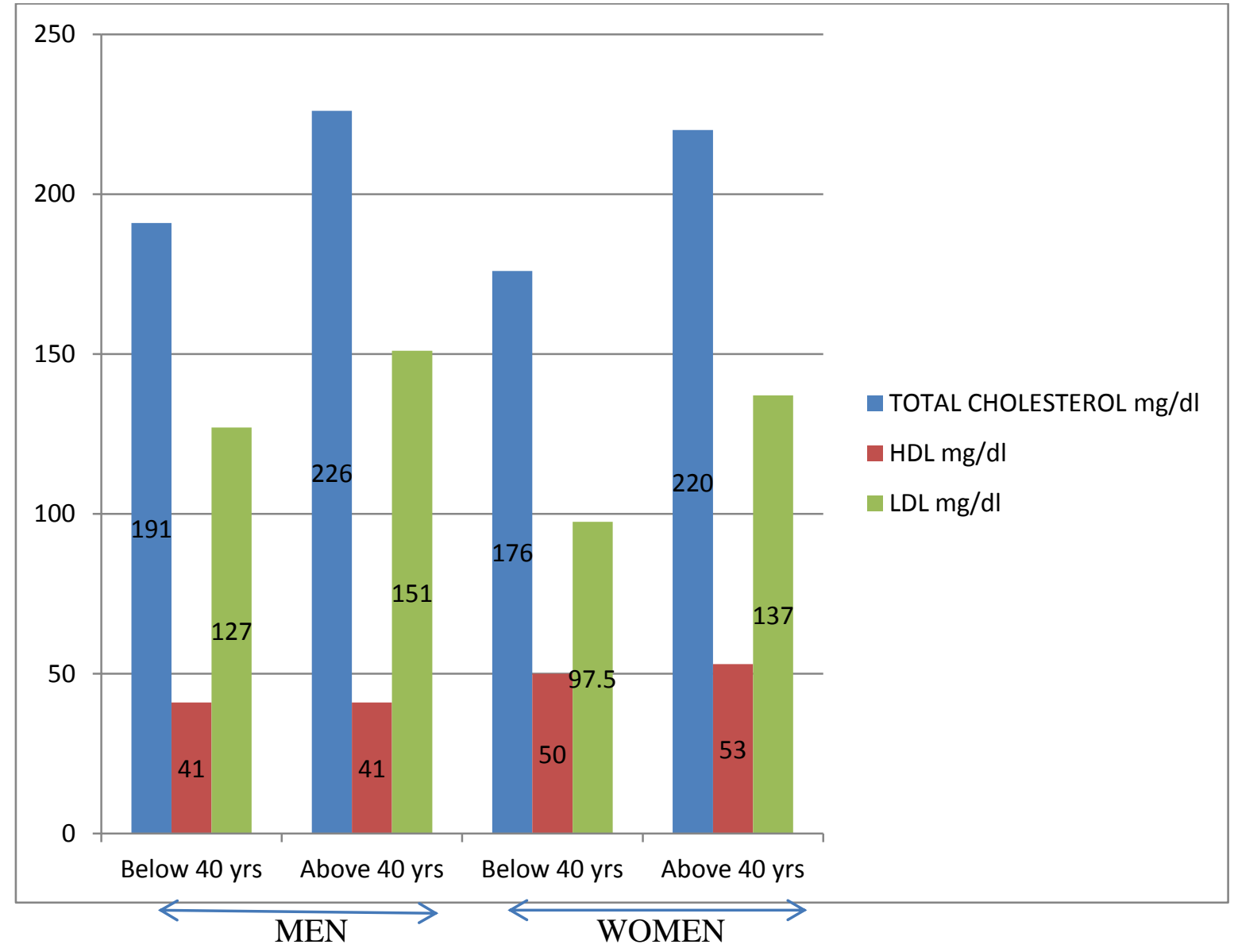




\section{JMSCR Vol||06||Issue||09||Page 241-249||September}

Chart-2B: Histogram Showing Mean Comparison between men and Women Diabetic patients with mean Total Cholesterol, HDL and LDL Cholesterol (mg/dl) Level

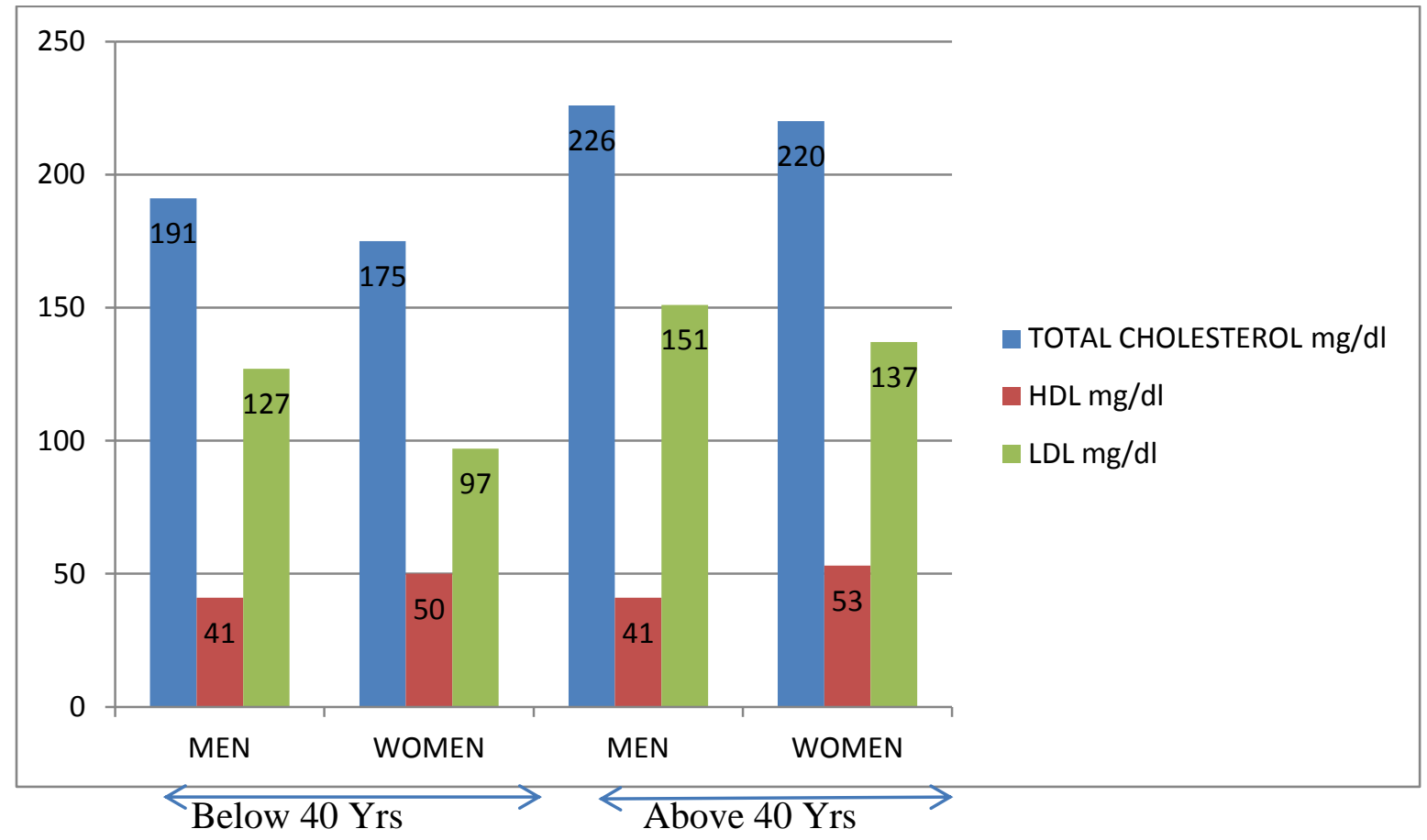

\section{For Table IIA and IIB}

Observation of serum analysis for total cholesterol, HDL cholesterol and LDL cholesterol on diabetic patients in men and women, below and above 40 yrs of age

Table IIA The table showing men total cholesterol, HDL cholesterol and LDL cholesterol (mg/dl) in type 2 diabetic patients.

\begin{tabular}{|l|c|c|c|c|c|}
\hline GROUP & & NO OF PTS. & $\begin{array}{c}\text { TOTAL CHOLESTEROL } \\
(\mathrm{mg} / \mathrm{dl})\end{array}$ & $\begin{array}{c}\text { HDL } \\
\mathrm{Mg} / \mathrm{dl}\end{array}$ & $\begin{array}{c}\text { LDL } \\
\mathrm{Mg} / \mathrm{dl}\end{array}$ \\
\hline MEN & Below 40 yrs & 20 & 191 & 41 & 127 \\
\hline & Above 40 yrs & 20 & 226 & 41 & 151 \\
\hline WOMEN & Below 40 yrs & 20 & 175 & 50 & 97.5 \\
\hline & Above 40 yrs & 20 & 220 & 53 & 137 \\
\hline
\end{tabular}

Table-2B Comparison between men and women diabetic patients total cholesterol HDL, and LDL level

\begin{tabular}{|l|c|c|c|c|c|}
\hline GROUP & NO OF PTS. & $\begin{array}{c}\text { TOTAL } \\
\text { CHOLESTEROL }\end{array}$ & $\begin{array}{c}\text { HDL } \\
\mathrm{Mg} / \mathrm{dl}\end{array}$ & $\begin{array}{c}\text { LDL } \\
\mathrm{Mg} / \mathrm{dl}\end{array}$ \\
\hline BELOW 40 YRS & MEN & 20 & 191 & 41 & 127 \\
\hline & WOMEN & 20 & 175 & 50 & 97 \\
\hline ABOVE 40 YRS & MEN & 20 & 226 & 41 & 151 \\
\hline & WOMEN & 20 & 220 & 53 & 137 \\
\hline
\end{tabular}


Chart-3: Histogram Showing means total Cholesterol, HDL and LDL Cholesterol (in mg/dl) in Type-2 Diabetic Male Patients

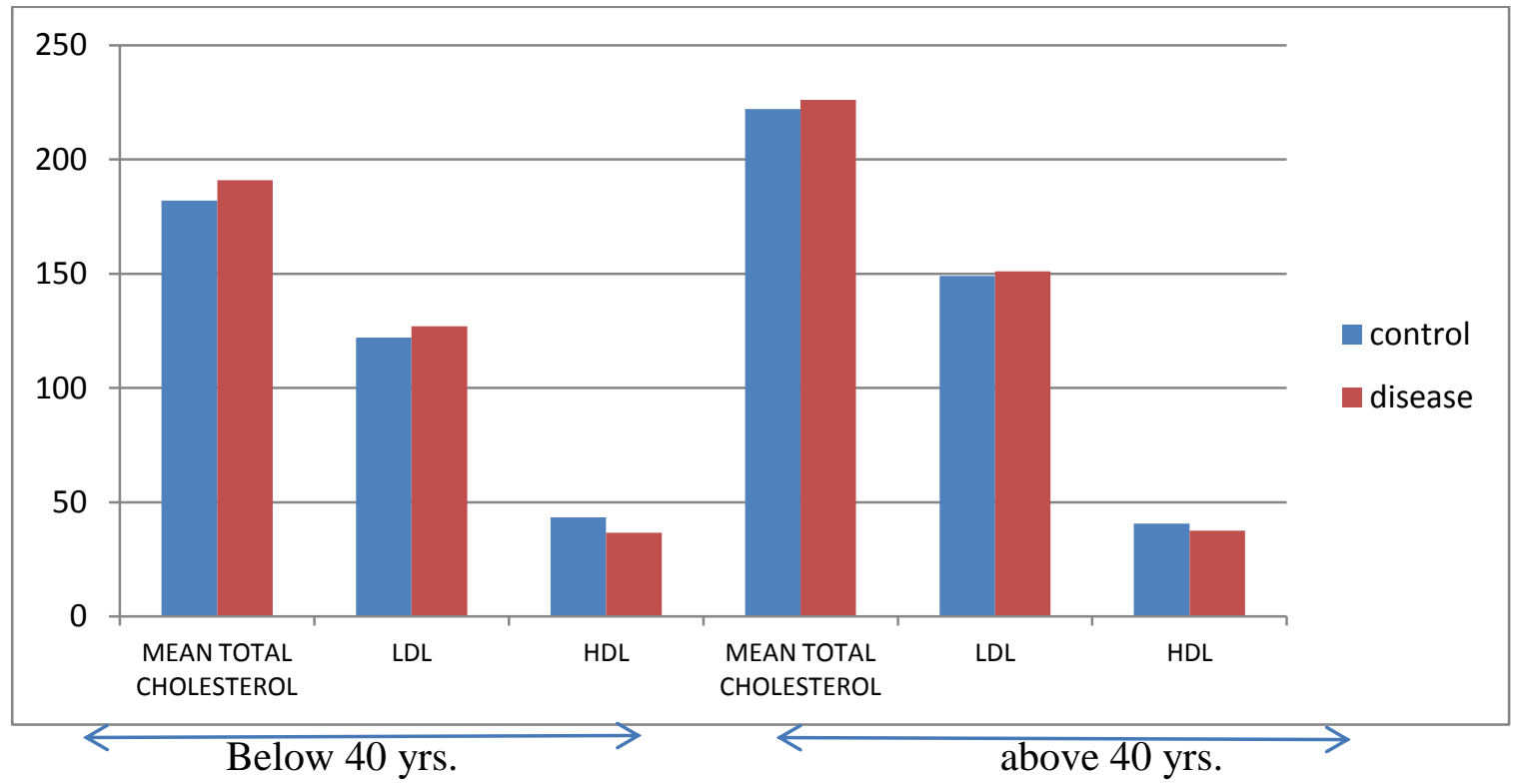

Chart-3: Histogram showing means total cholesterol, HDL, LDL cholesterol (in mg/dl) in type-2 diabetic Female patients.

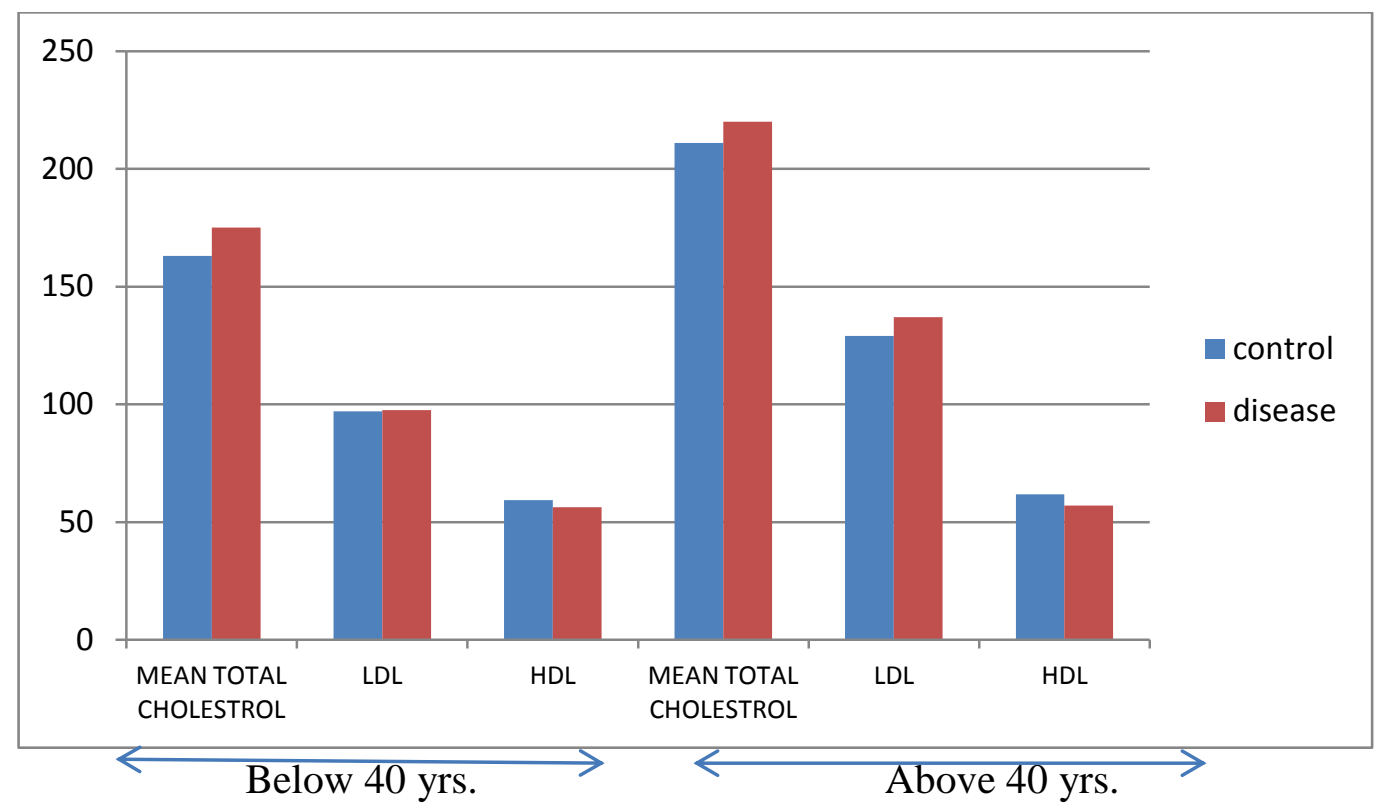

Table-3: Showing comparison of total cholesterol, HDL, LDL cholesterol (mg/dl) in diabetic and controls.

\begin{tabular}{|l|c|l|c|c|c|c|c|}
\hline GROUP & AGE GROUP & & $\begin{array}{c}\text { NO. OF } \\
\text { POINTS }\end{array}$ & $\begin{array}{c}\text { MEAN TOTAL } \\
\text { CHOLESTEROL MG/DL }\end{array}$ & LDL & HDL & SIGNIFICANCE \\
\hline MEN & BELOW 40 YRS & $\mathrm{C}$ & 20 & 182 & 122 & $47+-3.62$ & Significant \\
\hline & & $\mathrm{D}$ & 20 & 191 & 127 & $41+-4.40$ & Significant \\
\hline & ABOVE 40 YRS & $\mathrm{C}$ & 20 & 222 & 149 & $45+-4.25$ & Significant \\
\hline & & $\mathrm{D}$ & 20 & 226 & 151 & $41+-3.42$ & Significant \\
\hline WOMEN & BELOW 40 YRS & $\mathrm{C}$ & 20 & 163 & 97 & $54+-5.36$ & Significant \\
\hline & & $\mathrm{D}$ & 20 & 175 & 97.5 & $50+-6.25$ & Significant \\
\hline & ABOVE 40 YRS & $\mathrm{C}$ & 20 & 211 & 129 & $57+-4.78$ & Significant \\
\hline & & $\mathrm{D}$ & 20 & 220 & 137 & $53+-4.10$ & Significant \\
\hline
\end{tabular}

C-control; D-diabetic Patients; S.D-standard deviation ; S-Significant. 
From the observation of table-3, it appears that high density lipoprotein cholesterol(HDL) level in diabetic patients is significantly lowered compared to the control of the same age group in both men and women groups, although the levels of HDL cholesterol are within normal range.

Total cholesterol level is slightly raised in women of both age group below 40 yrs categories; but marginally raised in men category in both are group compared to the respective age-matched control.

LDL cholesterol is also marginally different to that of control; so both total cholesterol and LDL cholesterol level is not significantly different from the controls.

\section{Discussion}

Diabetes mellitus, particularly non-insulin dependent diabetes mellitus (NIDDM) is going to be a big problem in developing countries .In India it is like an epidemic, so the morbidity and mortality arising out of DM has become a major health problem, and also economical burden on the society is huge, due to long course and deadly complications of diabetes.

1-Serum cholesterol in controls-In both men and women of age above 40 years, serum total cholesterol was found to be higher than in below 40 years of age (Table-IA). Cholesterol level is already known to increase with increasing age (kornerup et al.., 1950). In our study, the women below age group of 40 years were having lower serum total cholesterol level than men of same age groups. But after 40 years of age women showed a sharp rise in its level. (Table-IB).In this age group the difference in the serum total cholesterol level in men and women both were not significant. Havel et al (1982)also had observed a sharp rise in the level of serum total cholesterol in women after the $5^{\text {th }}$ decade of life.

2-Serum cholesterol level in diabetics-In diabetic patients, the mean total serum cholesterol concentration in men and women both were within normal limits (Table III). This observation is in accordance with those of Nikkils et al (1978),
Eckel et al (1981), Harano Y et al(1996)also observed no high level of cholesterol in controlled diabetics. As a Yama $\mathrm{K}$ et al also observed no change in level of non HDL cholesterol in diabetics. Although some workers James R W et al (1991); Arisue K et al(1994), Calmarza P et al (1999) found high cholesterol level in poorly controlled diabetes. In our study, our finding of unaltered level of cholesterol in diabetics may be due to better control of diabetes.

3-Serum HDL cholesterol level in normal-Serum HDL cholesterol level in normal persons below 40 years and above 40 years of age are given in table 1A . In control male HDL cholesterol level was significantly the same in both age groups under study. But in female there was significant increase in its serum level. The age effect on serum HDL in case of normal male and female both in our study was in accordance with Heise et al (1980). A failure to detect a decrease in HDL levels in women at ages after menopause argues against a major influence of oestrogen levels in older adult women. A gonadotrophin effect on HDL may be responsible for maintenance of HDL (kress et al. 1979).According to the table 1B, the serum HDL cholesterol concentration in female was more than male of comparable ages. This result is in accordance with Ronald M krauses (1982).

4-serum HDL cholesterol in diabetic patients:

Table IIA indicates that HDL cholesterol level between diabetics person were no altered in men and women of ages below and above forty years. But (table III)it is lower in comparison to the respective age group of control and this is significant. In our study this indicates decreased level of HDL cholesterol in type 2 diabetic person in relation to the control. This observation is in accordance with lopes and Vivell et al (1971) terzieva $\mathrm{T}$ S et al(1990), al Mertitaseb N. et al(1991); Verges B et al(1992); Harmo $\mathrm{Y}$ et al(1996) and laakso $M$ et al(1997) observations other observers also found relationship between low HDL cholesterol concentration and type 2 diabetes mellitus contrary to this Asayana et al found increased level of HDL in diabetics 
patients. Although level of HDL in men below and above 40 years group are same and also not much altered in both age groups in female diabetics.

5: Serum LDL cholesterol in normal and diabetic: In our study LDL cholesterol in both sexes increased with ages. Male have higher LDL cholesterol level than female in both the age groups table (IA-IIb). The level of LDL cholesterol in diabetics were significantly same as in the normal in both sexes. Asayama k et al also observed unaltered non HDL cholesterol level in diabetics patients. But contrary to this Laakso M et al (1997) found low level of LDL cholesterol in female type 2 diabetics with gall stone. Some workers also observed high level of LDL in diabetics (Dimitriadis E et al 1996, al-Mutitaseb N et al 1996).A study conducted by Otamere HO et al also documented an increase in total cholesterol, LDL which was similar to the findings in this study. ${ }^{9}$ Studies such as Albrki $\mathrm{WM}$ et al also documented decreased level of HDL which was picture in our study. ${ }^{10}$

6: Severity of diabetes and cholesterol: There was no significant alteration in total cholesterol, HDL cholesterol and LDL cholesterol level due to the severity of the disease al-Muhtaseb $\mathrm{N}$ et al (1991) also found no significant correlation with blood sugar level and cholesterol level in diabetic women.

7:From the chart it is clear that HDL cholesterol level changes is not altered in diabetic group having the disease for more than 5 yrs(5-10yrs) compared to that in the 1-5 yrs duration. And also total cholesterol level and LDL cholesterol levels are also not much altered.

\section{Conclusion}

In the view of the high incidence of ischaemic heart disease in diabetes mellitus, we determined particularly high density liproprotein cholesterol, along with total cholesterol and LDL cholesterol. HDL cholesterol is known to have a protective role in formation of atherosclerosis also known as "cardio protective cholesterol". Its high level is cardio protective. So in this study we tried to find out any alteration in the level of HDL in diabetic patients. Eighty non-insulin dependent diabetic patients and eighty comparable age group (28-60 yrs) controls of both sexes were studied, our findings in short are as follow:

1) A rise in serum total cholesterol with age was observed in normal males and females. After forty years of age, there was a sharp rise in the serum cholesterol level among normal females.

2) In normal female HDL cholesterol level was higher than that of normal male of the same age groups.

3) LDL cholesterol level in normal was found to have same relation with age and sex as cholesterol.

4) Serum total cholesterol levels in diabetic patients(type 2-NIDDM) was higher in above 40 years group than below 40 years group in both male and female(table-IIa) but in comparison to controls similar age and sex group, there was no significant alteration in the total cholesterol level of diabetic patients.

5) Serum HDL cholesterol level in diabetic group was significantly lower to controls of comparable age group in both male and female.

6) Serum HDL cholesterol level in diabetic groups of male and female were found not to be influenced by the severity or duration of the disease.

7) Serum LDL cholesterol level in diabetic group of male and female was not significantly altered.

\section{References}

1. Harrison's principals of internal medicine, $18^{\text {th }}$ ed. $2017 ; 2: 2967-8$

2. Whiting DR, Guariguata L, Weil C,Shaw J.IDF diabetes atlas:global estimates of the prevalence of diabetes for 2011 and 2030. Diabetes research and clinical practice 2011;94(3):311-21 
3. Anjana RM, Pradeepa R, Deepa M, Sudha $\mathrm{V}$, Unnikrishnan $\mathrm{R}$, et al.ICMR-INDIAB collaborative study group: Prevalence of diabetes and prediabetes (impaired fasting glucose and or impaired glucose tolerance) in urban and rural India: phase 1 results of the Indian Council of Medical ReasearchINdia DIABetes (ICMR-INDIAB) study. Diabetologia 201;54(12):3022-7.

4. Ramachandran A, Snehalatha C,Kapur A, Vijay V,Mohan V,Das AK,et al. Diabetes Epidemiology study group in India(DESI).High prevalence of diabetes and impaired glucose tolerance in India:National Urban Diabetes Survey. Diabetologia.2001;44(9):1094-101.

5. Verma NP. Mehta SP, Madhu S, Mather HM,Keen H. Prevalence of known diabetes in an urban Indian environment: the Darya Ganj diabetes survey. Brit medic J (clinic Res ed.) 1986;293(6544):423.

6. Mohan V, Deepa M, Deepa R,Shanthirani CS,Farooq S, Ganesan A, et al.Secular trends in the prevalence of diabetes and impaired glucose tolerance in urban South India- the Chennai Urban Rural Epidemiology Study(CURES-17). Diabetologia.2006;49(6):1175-8.

7. Parikh RM.Diabetes and metabolic syndrome:Clinical Research and Reviews 2010;4:10-12.

8. Harrison's Principals of Internal Medicine, $18^{\text {th }}$ edition,ch 344;2985-6

9. Otamere HO,Aloamaka CP,Okokhere PO, Adisa WA. Lipid profile in diabetes mellitus; what impact has age and duration. Britt J Pharmacol Toxicol. 2011;2(3):135-7

10. Albrki WM Elzouki AN,EI-Mansoury AM,Tashani OA.Lipid profiles in Libyan type II diabetics. J Sci APPLS 2007;1:1823. 